\title{
Article \\ The Influence of Pickling Treatment Parameters on the Surface State and Pre-Passivation Behavior of Super 13Cr Martensitic Stainless Steel
}

\author{
Hui Dong ${ }^{1, *}$, Zhuo Luo ${ }^{1}$, Yan Han ${ }^{2, *}$, Yan-Ming Liu ${ }^{1}$, Liang Sun ${ }^{1}$ and Wen-Yan Zhai ${ }^{1}$ \\ 1 Xi'an Key Laboratory of High Performance Oil and Gas Field Materials, \\ School of Materials Science and Engineering, Xi'an Shiyou University, Xi'an 710065, China; \\ lz1047102744@163.com (Z.L.); ymliu@xsyu.edu.cn (Y.-M.L.); lsun@xsyu.edu.cn (L.S.); \\ 180606@xsyu.edu.cn (W.-Y.Z.) \\ 2 State Key Laboratory for Performance and Structure Safety of Petroleum Tubular Goods and Equipment \\ Materials, CNPC Tubular Goods Research Institute, Xi'an 710077, China \\ * Correspondence: donghui@xsyu.edu.cn (H.D.); hanyan003@cnpc.com.cn (Y.H.); Tel.: +86-29-8838-2607 (H.D.); \\ +86-29-8188-7912 (Y.H.)
}

check for updates

Citation: Dong, H.; Luo, Z.; Han, Y.; Liu, Y.-M.; Sun, L.; Zhai, W.-Y. The Influence of Pickling Treatment Parameters on the Surface State and Pre-Passivation Behavior of Super 13Cr Martensitic Stainless Steel. Coatings 2022, 12, 127. https:// doi.org/10.3390/coatings12020127

Academic Editor: László A. Péter

Received: 10 December 2021

Accepted: 19 January 2022

Published: 23 January 2022

Publisher's Note: MDPI stays neutra with regard to jurisdictional claims in published maps and institutional affiliations.

Copyright: (C) 2022 by the authors. Licensee MDPI, Basel, Switzerland. This article is an open access article distributed under the terms and conditions of the Creative Commons Attribution (CC BY) license (https:// creativecommons.org/licenses/by/ $4.0 /)$

\begin{abstract}
As a pre-treatment process in the pre-passivation of stainless steel, pickling treatment has a significant effect on the formation of the pre-passivation film. Thus, the surface composition and defects of Super 13Cr martensitic stainless steel (Super 13Cr) were evaluated under different pickling parameters to further improve the corrosion resistance of the pre-passivation film. The samples were prepared using the acid immersion method and by changing the immersion duration and the acid concentration. The inclusion and chemical composition on the Super $13 \mathrm{Cr}$ surface were characterized via a scanning electron microscope (SEM) and energy-dispersive X-ray spectroscopy (EDS). The pickling treatment contributes little to the morphology, dimension, and other characteristic parameters of the inclusions. With the increasing duration and acidification concentration, the $\mathrm{Cr}$ content on the surface of Super $13 \mathrm{Cr}$ increases initially and then decreases. By contrast, the $\mathrm{Fe}$ content decreases initially and then increases. The pickling parameters corresponding to the lowest Fe content and the highest $\mathrm{Cr}$ content are identical, i.e., the exposure duration is $50 \mathrm{~s}$ and the acid concentration is $48 \mathrm{~g} / \mathrm{L}$. The pickling treatment in this case could be divided into two stages: outer film dissolution and inner film dissolution. The pickling parameters basically contribute little to the defects of martensitic stainless steel but can significantly affect the surface $\mathrm{Cr}$ and Fe content. Retaining the $\mathrm{Cr}$-enriched inner layer could improve the content of $\mathrm{Cr}$ in the pre-passivation film and then improve the corrosion resistance of the film. Thus, compared with the original sample with native film, the corrosion resistance of the sample with a Cr-enriched inner layer improved by a factor of about 40 .
\end{abstract}

Keywords: Super 13Cr martensitic stainless steel; pre-passivation; pickling treatment; corrosion resistance

\section{Introduction}

With the development of oil and gas fields, the service environment of pipes is becoming more and more rigorous. Super 13Cr martensitic stainless steel (Super 13Cr) (API Spec 5CRA-2010) is becoming a preferred material in high $\mathrm{CO}_{2}$ environments with low $\mathrm{H}_{2} \mathrm{~S}$ because of natural passivation in the atmosphere [1-3]. However, the pitting induced by defects and other factors obviously induces the sensitivity of stress corrosion cracking (SCC) [4-6]. As a result, stress corrosion cracking is a challenge that plagues the application of Super 13Cr [7-10].

Recently, some methods, such as the chemical composition, the molding process, and the post-treatment process, were selected to attempt to improve the pitting corrosion and stress corrosion cracking resistance of Super 13Cr [11-13]. On the basis of traditional Super 
$13 \mathrm{Cr}$, commercial Super $13 \mathrm{Cr}$ is fabricated by increasing the mass fraction of the elements $\mathrm{Ni}$ and Mo and reducing the carbon content [14-16]. Meanwhile, Super 13Cr contains a fraction of inverter austenite that can improve its corrosion resistance [17-20]. Increasing the $\mathrm{Cr}$ content in stainless steel is a general and apparent method to improve the corrosion resistance performance [21,22], such as in the $15 \mathrm{Cr}$ and $17 \mathrm{Cr}$ stainless steel developed by JFE Holdings, Inc. (Tokyo, Japan). Compared with the Super 13Cr, these two stainless steels both significantly improve the corrosion resistance [23]. However, compared with Super $13 \mathrm{Cr}$, the prices of $15 \mathrm{Cr}$ and $17 \mathrm{Cr}$ stainless steel increase by about $20 \%$ and $40 \%$, respectively, and these price increases are equivalent to 1-2 times the price of ordinary P110 pipelines. Therefore, other methods need to be developed to improve the pitting resistance of Super 13Cr while maintaining the current cost.

Generally, the thickness of the natural passivation film on the stainless-steel surface is within the range of 1-3 nm. Nanoscale films can significantly improve the corrosion resistance of stainless steel [24]. If the thickness of this passivation film increases, the corrosion resistance of the stainless steel should be further improved. Based on this idea, the austenitic stainless steel has adopted a pre-passivation process to prepare a prepassivation film on the surface, which has been widely applied [25-28]. Due to the low $\mathrm{Cr}$ content of Super 13Cr, instead of the acid pre-passivation, alkaline liquor is an ideal pre-passivation solution. However, the reports on Super $13 \mathrm{Cr}$ passivation to date have focused primarily on the effect of the film generated during the application on the corrosion resistance $[17,29,30]$. The films in these reports are actually the corrosion product caused by the corrosion medium during application. Thus, the corrosion resistance of pre-passivated Super $13 \mathrm{Cr}$ to date is not yet clear. As one of the main processes before pre-passivation, pickling treatment could improve the pre-passivation efficiency. Unfortunately, the change in surface parameters, such as the native film and the defects, during picking treatment is unclear, which is the basis for the preparation of high corrosion resistance film.

In this paper, the elements and the inclusions on a Super $13 \mathrm{Cr}$ surface under different pickling parameters are elaborated in detail. Moreover, an electrochemical test was performed on the pre-passivation samples with different pickling parameters to sketch out the effect of the pickling parameters on the corrosion resistance of the Super 13Cr.

\section{Experimental}

\subsection{Materials}

The material used in this case is Super 13Cr (Baoshan Iron \& Steel Co., Ltd., Shanghai, China), and its chemical composition is shown in Table 1. The chemical composition meets the requirements of the API Spec 5CRA-2010. The sample size used in this case is $40 \mathrm{~mm} \times$ $10 \mathrm{~mm} \times 3 \mathrm{~mm}$. Before the test, the samples were ground, step by step, with 500\#, 800\#, and 1200\# SiC sandpaper, and then polished with a diamond polishing fluid with a particle size of $0.5 \mu \mathrm{m}$. The samples were put into an ultrasonic cleaner and washed with acetone and anhydrous ethanol.

Table 1. The chemical composition of Super $13 \mathrm{Cr}(\mathrm{wt} \%)$.

\begin{tabular}{ccccccccc}
\hline $\mathbf{C}$ & $\mathbf{S i}$ & $\mathbf{M n}$ & $\mathbf{P}$ & $\mathbf{S}$ & $\mathbf{C r}$ & $\mathbf{N i}$ & $\mathbf{M o}$ & $\mathbf{F e}$ \\
\hline 0.017 & 0.23 & 0.49 & 0.012 & 0.0043 & 13.3 & 5.01 & 1.85 & Bal. \\
\hline
\end{tabular}

\subsection{The Pre-Treatment in Acid Solution and Pre-Passivation}

An alkaline solution of $\mathrm{NaOH}$ with a concentration of $1 \mathrm{~g} / 100 \mathrm{~mL}$ was employed to remove the grease on the sample surface, carried out at a temperature of $90{ }^{\circ} \mathrm{C}$ with a duration of $5 \mathrm{~min}$. The degreased samples were corroded in a $\mathrm{H}_{2} \mathrm{SO}_{4}$ solution with a concentration of $48 \mathrm{~g} / \mathrm{L}$. The immersion duration was selected, including 0, 30, 50, 70, 90, and $110 \mathrm{~s}$, respectively.

Five defects and matrix positions on the surface of the original sample were observed and marked, and then the sample was pickled in the acid solution for a duration of $30 \mathrm{~s}$. The 
five identical defects on the surface were profiled after the $30 \mathrm{~s}$ pickling treatment with a scanning electron microscope (TESCAN VEGAIIXMU, Czech TESCAN, Czech) and energy spectroscopy (OXFORD7718, Oxford Instruments, London, United Kingdom). Likewise, these five defects were observed after 50,70, 90, and 110 s pickling treatments, respectively. The change tendency of the defects and the chemical composition on the surface of the Super 13Cr were sketched to research the effect of pickling duration on the surface of the Super $13 \mathrm{Cr}$.

In addition, six acid concentrations were also prepared to elaborate the surface state of the Super 13Cr, including 0, 29, 48, 66, 85, and $103 \mathrm{~g} / \mathrm{L}$, respectively. The perfectly similar to immersion duration method was employed to profile the in-suit defects and the chemical composition.

A pre-passivated solution including $70 \mathrm{~g} \mathrm{NaOH}, 15 \mathrm{~g} \mathrm{Na}_{3} \mathrm{PO}_{4}, 0.5 \mathrm{~g} \mathrm{NaNO}$, and $500 \mathrm{~mL}$ distilled water was allocated. The solution was stirred fully with a glass rod until all the solute completely dissolved. Three typical samples with pickling parameters of $48 \mathrm{~g} / \mathrm{L}-50 \mathrm{~s}, 103 \mathrm{~g} / \mathrm{L}-110 \mathrm{~s}$ and the original sample were pre-passivated at a temperature of $100{ }^{\circ} \mathrm{C}$. The pre-passivation dwell time was $30 \mathrm{~min}$.

\subsection{Electrochemical Test}

A Corrtest CS235 (Jiahang Bochuang Technology, Beijing, China) electrochemical workstation was employed to carry out the electrochemical test. A three-electrode system was used. The Super 13Cr sample, two graphite electrodes, and a saturated calomel electrode (SCE) were used as the working electrode, the counter electrode, and the reference electrode, respectively. The corrosion performance of the Super $13 \mathrm{Cr}$ in seawater was examined, and thus, a $3.5 \% \mathrm{NaCl}$ solution was used in this case. The electrodes were stabilized for $30 \mathrm{~min}$, and then the open circuit potential (OCP) was recorded. Alternating current $(\mathrm{AC})$ impedance and the polarization curve tests of the three samples were carried out after the pickling passivation treatment. All tests were carried out at room temperature and at atmospheric pressure.

The initial potential measured by the electrochemical polarization curve was $-500 \mathrm{mV}$ (relative to the open circuit potential), the termination potential was $+1500 \mathrm{mV}$ (relative to the open circuit potential), and the scanning speed was $0.33 \mathrm{mV} / \mathrm{s}$. The frequency range of the AC impedance spectrum was $10^{-2}-105 \mathrm{~Hz}$, and the amplitude of the impedance measurement signal was a sinusoidal wave of $10 \mathrm{mV}$.

\subsection{Observation of the Microstructure}

Abrasive papers of different types were employed to grind the samples successively. After that, polishing was finished with a $0.5 \mu \mathrm{m}$ diamond on micro-cloth. The samples were corroded in a solution containing $4 \% \mathrm{HNO}_{3}, 4 \% \mathrm{HF}$, and $92 \%$ distilled water. Then, the metallographic microstructures were observed with an optical microscope (BX6, Olympus, Tokyo, Japan).

The surface chemical composition and defects of the Super $13 \mathrm{Cr}$ were observed with a scanning electron microscope (SEM, JSM-6390A, JEOL, Tokyo, Japan), equipped with energy-dispersive $\mathrm{X}$-ray spectroscopy.

\section{Results}

\subsection{Microstructure of Super $13 \mathrm{Cr}$}

The metallographic microstructure of the Super $13 \mathrm{Cr}$ is shown in Figure 1. The results indicate that a typical tempered martensite microstructure was observed. High strength and appropriate toughness are necessary properties of the metal used in oil-field tests, especially for the downhole tubing. Thus, the steel used in oil fields is generally heattreated, including quenching and tempering, and a tempered microstructure could be achieved in the Super $13 \mathrm{Cr}$. The matrix phase still keeps the original quenched-slat shape after tempering, distributing some $\varepsilon$-carbides. The $\varepsilon$-carbides improves the strength and relieves the negative effect of the carbon precipitation on the strength. In addition, the 
carbon precipitation from the matrix phase improves the toughness and the plasticity of the steel. Therefore, the Super $13 \mathrm{Cr}$ used in this case had an appropriate toughness and a high strength.

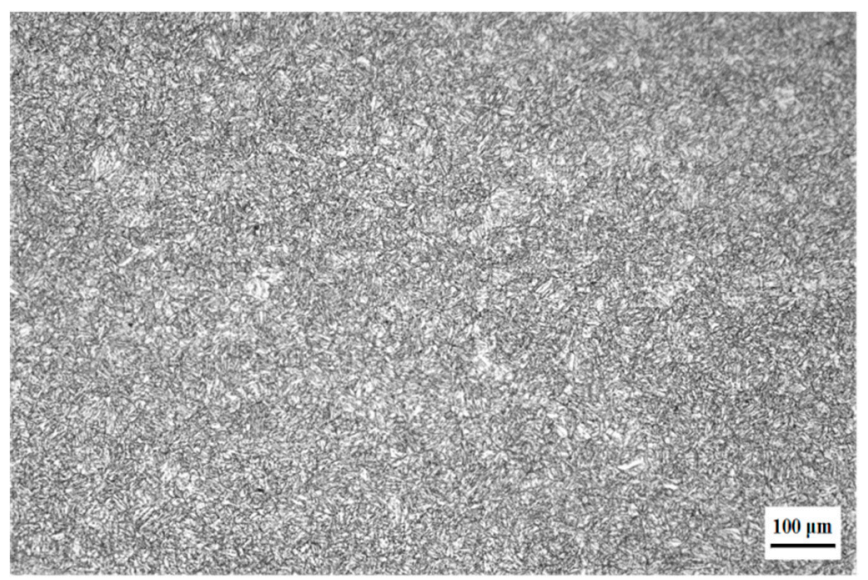

(a) Low magnification

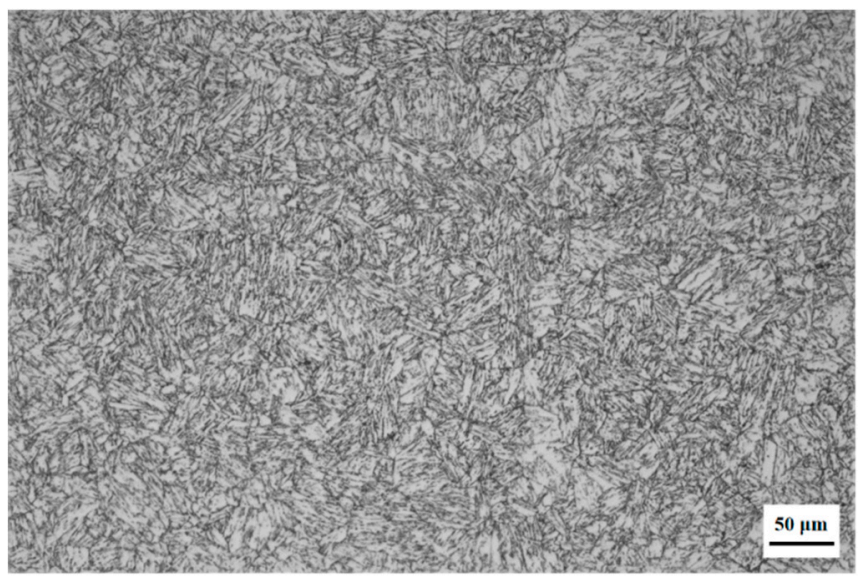

(b) High magnification

Figure 1. Metallographic microstructure of Super 13Cr: (a) low magnification, (b) high magnification.

\subsection{Surface Characteristic Depended on the Acidification Duration}

In order to accurately represent the influence of acidification duration on the defects on the Super $13 \mathrm{Cr}$ surface, five defects on one sample surface in each pickling duration were observed. One representative defect in each duration was employed to illustrate the evolving characteristics of the defects. In addition, the results of the EDS spectra in this case were all achieved by the averaging of the five values.

The defect morphologies with different pickling durations are shown in Figure 2. The results show that the inclusion on the surface of the Super $13 \mathrm{Cr}$ is spherical, with a diameter of about $15 \mu \mathrm{m}$. The inclusion still retained the spherical shape and the dimension, which indicates that the inclusion was independent of the pickling duration.

The EDS spectra of a representative inclusion with different pickling durations are shown in Figure 3. The results show that the inclusion mainly includes $\mathrm{Mg}, \mathrm{Al}$, and $\mathrm{O}$. The inclusions in the stainless steel were brought into the production process and the deoxidation process through mixing [31]. Al, as a strong oxidation metal, is the common deoxidant used in the production process of steel [32]. However, the amount of $\mathrm{Al}$ in the deoxidation process of molten steel was not used in this case, which would reduce the excess $\mathrm{Al}$ to form $\mathrm{Al}_{2} \mathrm{O}_{3}$ and react with the $\mathrm{MgO}$ existing in the molten steel to form $\mathrm{Al}$, $\mathrm{Mg}$ compound oxides, or magnesium and aluminum. Meanwhile, a fraction of aluminum dissolves in the molten steel during the smelting process, which constantly reacts with the dissolved oxygen and the surrounding oxides in the molten steel to form the inclusions of $\mathrm{Al}_{2} \mathrm{O}_{3}$ or $\mathrm{Al}_{2} \mathrm{O}_{3}-\mathrm{MgO}[33,34]$. Therefore, the inclusion in the Super $13 \mathrm{Cr}$ stainless steel in this case was $\mathrm{Al}_{2} \mathrm{O}_{3}-\mathrm{MgO}$. 
(a)

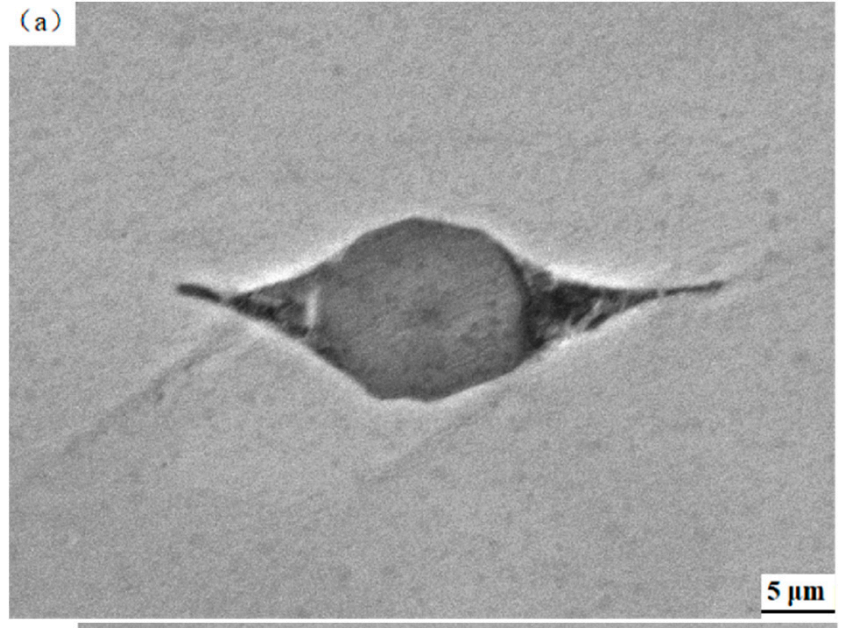

(c)

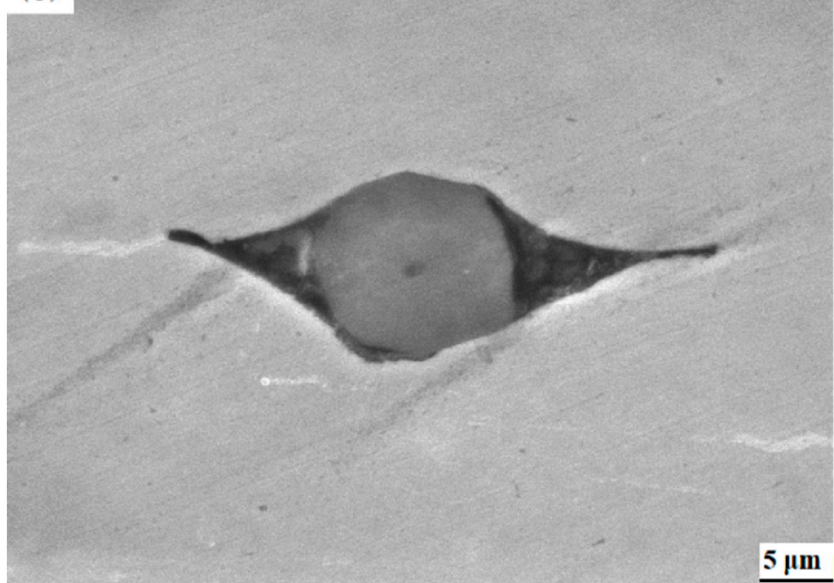

(e)

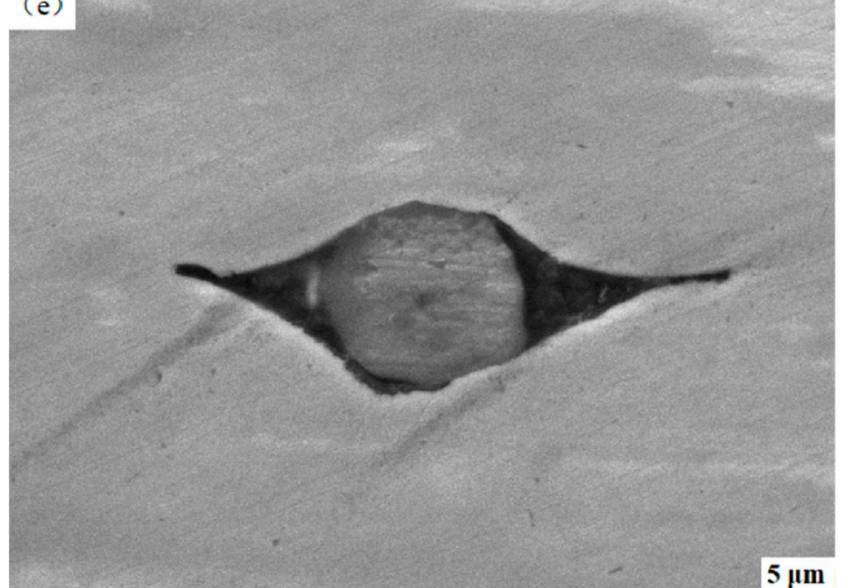

(b)

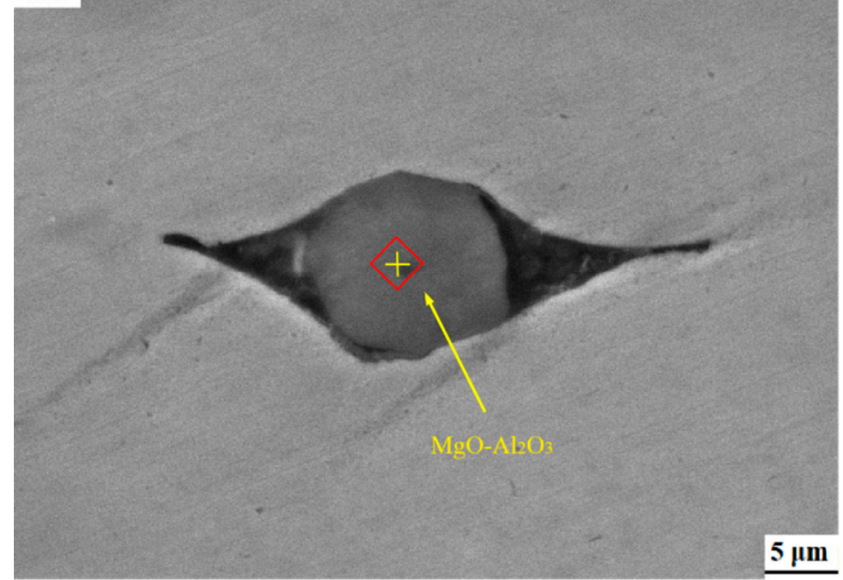

(d)

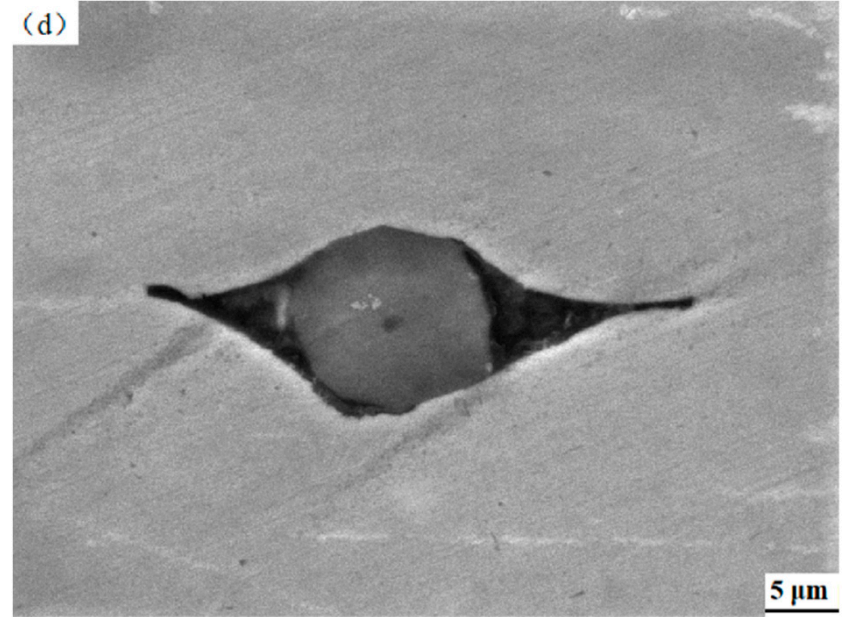

(f)

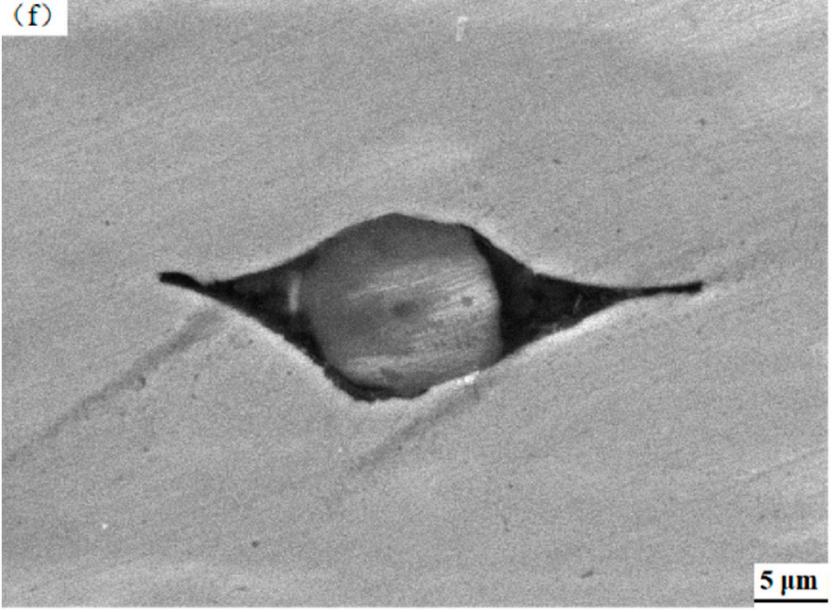

Figure 2. Inclusion morphologies with different acidification durations: (a) $0 \mathrm{~s}$; (b) $30 \mathrm{~s}$; (c) $50 \mathrm{~s}$; (d) $70 \mathrm{~s}$; (e) $90 \mathrm{~s}$; and (f) $110 \mathrm{~s}$. 


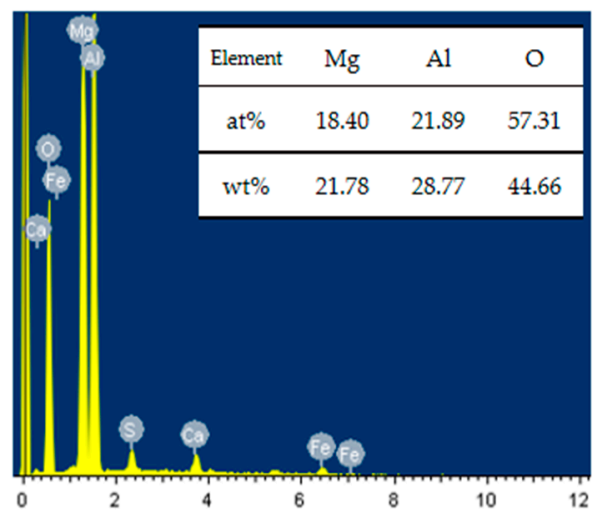

(a)

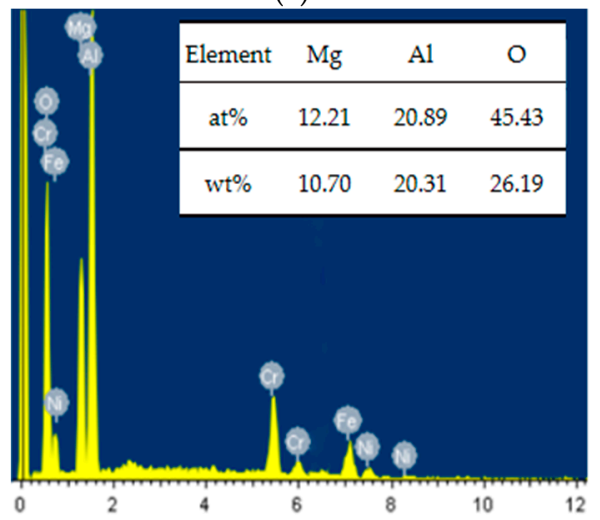

(d)

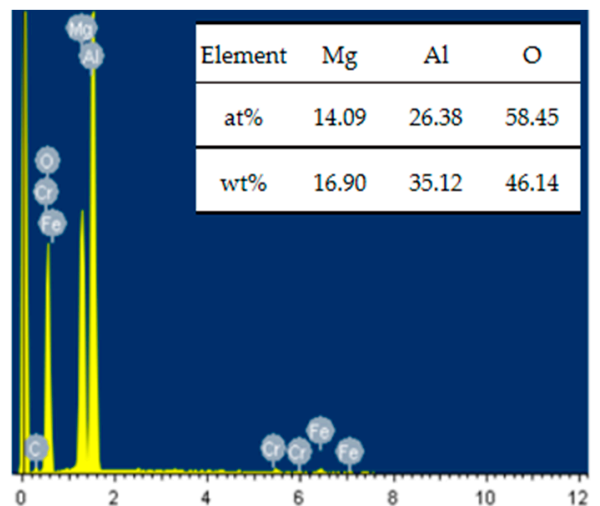

(b)

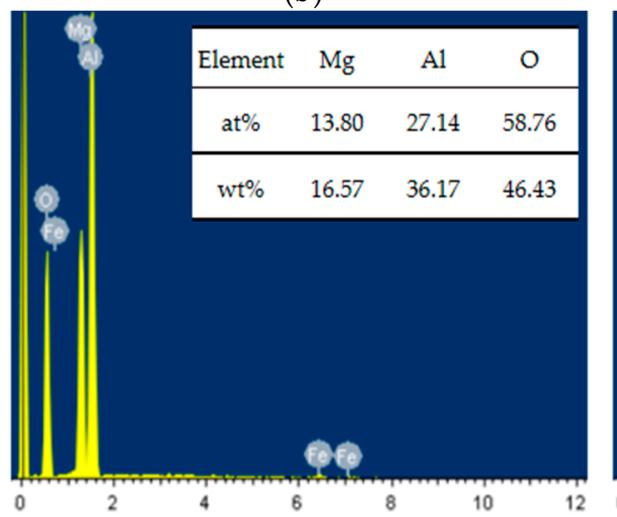

(e)

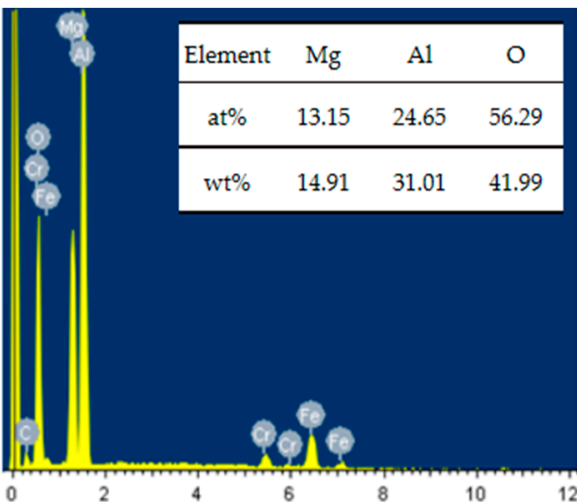

(c)

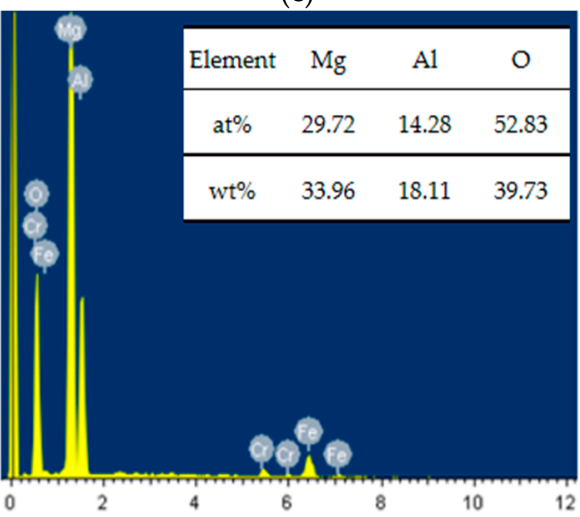

(f)

Figure 3. The EDS spectra of inclusions after different soaking durations: (a) $0 \mathrm{~s}$; (b) $30 \mathrm{~s}$; (c) $50 \mathrm{~s}$; (d) $70 \mathrm{~s}$; (e) $90 \mathrm{~s}$; and (f) $110 \mathrm{~s}$.

According to the pitting mechanism of stainless steel, inclusions are one of the main reasons for the stress corrosion cracking [35]. Therefore, $\mathrm{Al}_{2} \mathrm{O}_{3}-\mathrm{MgO}$ inclusions are the main reason for the destruction of the Super $13 \mathrm{Cr}$ surface passivation film. The properties of $\mathrm{Al}_{2} \mathrm{O}_{3}-\mathrm{MgO}$ inclusions are roughly similar to those of $\mathrm{Al}_{2} \mathrm{O}_{3}$. They have a high melting point, a high level of hardness, and a corrosion resistance to acids, which make it impossible for them to react significantly with a dilute sulfuric acid solution in a short time. Thus, the shape and the dimension of the inclusions during acidification in this paper basically did not change. In addition, the inclusion cloud did not fill with stainless steel surface defects; there was a fraction of pore areas between the inclusion periphery and the matrix phase. Due to the high corrosion resistance of the inclusion itself, the pitting corrosion of the stainless steel at the inclusion site may have been caused by the corrosion of the gap between the matrix phase and the inclusions. Therefore, the chemical elements in the gap, depending on the duration, were analyzed.

Figure $4 \mathrm{a}, \mathrm{b}$ show the different surface morphologies of the same defect before and after soaking in a dilute sulfuric acid solution, and Figure 4c,d show the EDS spectra corresponding to Figure $4 \mathrm{a}, \mathrm{b}$. According to Figure $4 \mathrm{c}, \mathrm{d}$, the chemical elements in the gap between the matrix phase and the inclusion are mainly Fe and Cr. Therefore, the gap could be regarded as the transition zone between the defect and the matrix metal. Based on the EDS spectra, the content of $\mathrm{Cr}$ and $\mathrm{Fe}$ in the gap changes significantly before and after soaking in a dilute sulfuric acid solution: the $\mathrm{Cr}$ content increases significantly, while the content of Fe decreases. On the one hand, the increasing $\mathrm{Cr}$ content would effectively improve the resistance to pitting at the defects of the matrix, but it would also decrease the sensibility of the stress corrosion cracking caused by pitting. 

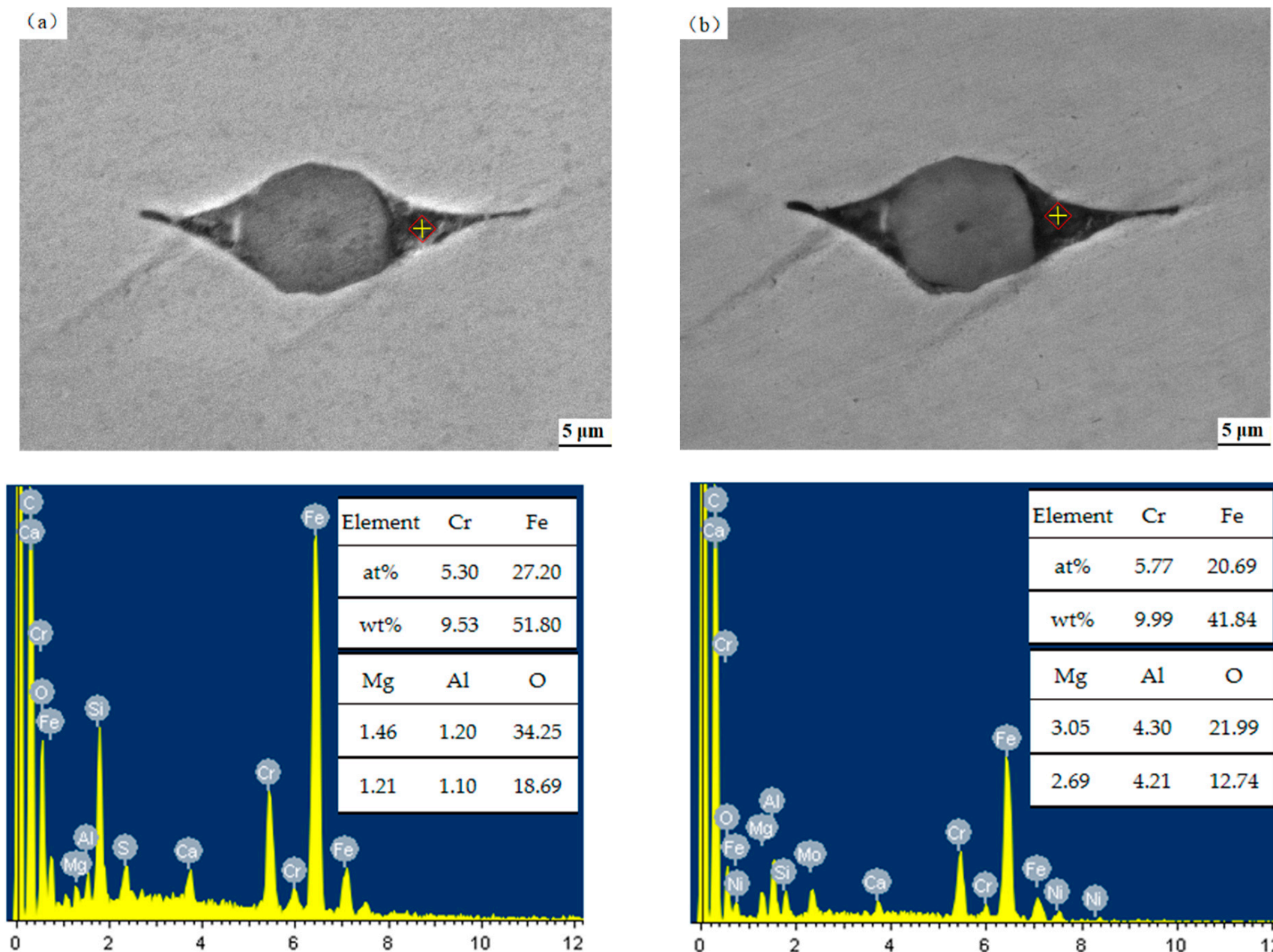

(c)

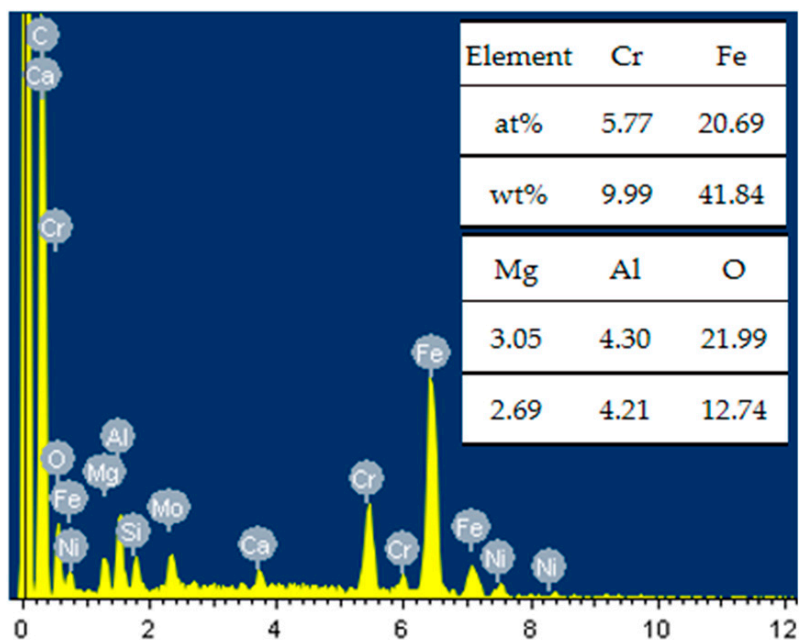

(d)

Figure 4. The morphologies of one defect with and without acidification and the corresponding EDS spectra. (a,c) before soaking; (b,d) after soaking with dwell time of $30 \mathrm{~s}$.

\subsection{Effect of Pickling Treatment on Super 13Cr Surface Chemical Composition}

The main purpose of stainless-steel pre-passivation is to prepare a thick pre-passivation film on the surface before application and improve the pitting corrosion resistance. Based on the film-formation mechanism of pre-passivation film, the chemical composition of the stainless-steel surface before pre-passivation has a significant impact on the composition of passivation film. Therefore, in order to maximize the corrosion resistance of the prepassivation film, the content of $\mathrm{Cr}$ in the pre-passivation film should be as great as possible. Thus, the influence of two acid-treatment factors on the surface chemical composition of stainless steel was studied in this paper. In order to improve accuracy, the accelerating voltage during the EDS spectrum test was designed to be $20 \mathrm{keV}$. The EDS spectra were tested on the stainless-steel surfaces with different acidification durations and acid concentrations. The results are shown in Figures 5 and 6 . In order to improve the reliability of the results, five zones were selected randomly after the pickling treatment, and the results are the average value of five regions in each group. 


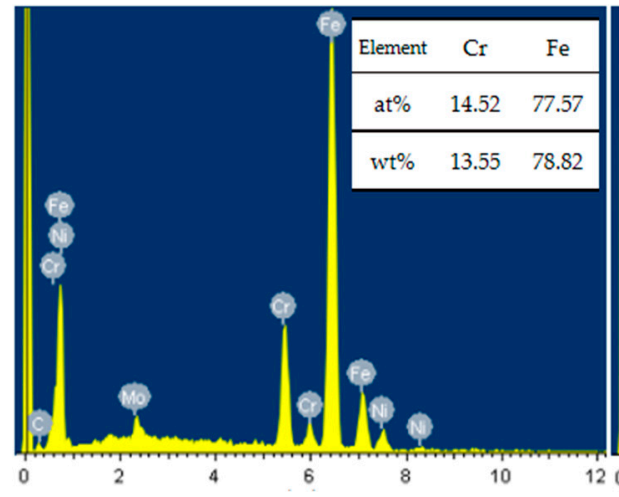

(a) $0 \mathrm{~s}$

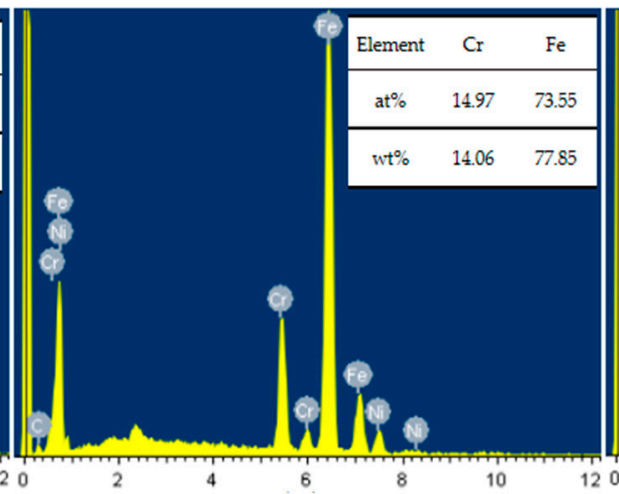

(b) $50 \mathrm{~s}$

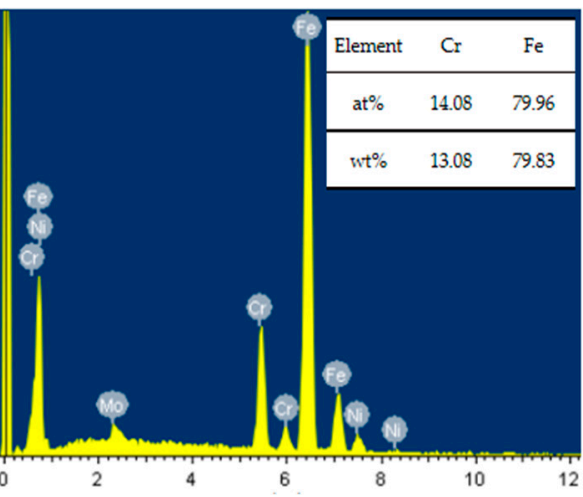

(c) $110 \mathrm{~s}$

Figure 5. The EDS spectra of samples with different acid treatment durations: (a) $0 \mathrm{~s}$; (b) $50 \mathrm{~s}$; and (c) $110 \mathrm{~s}$.

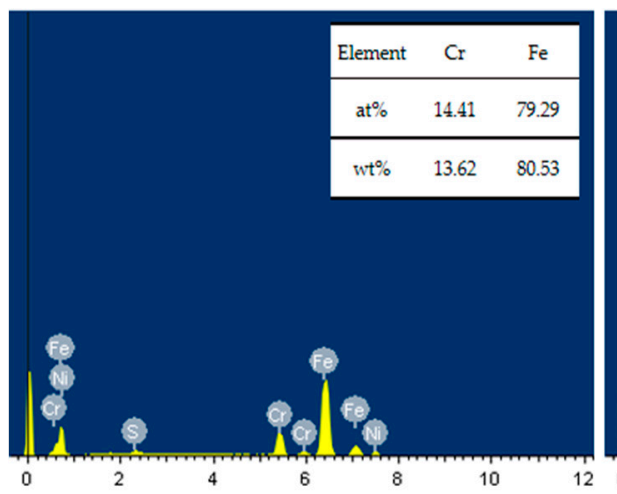

(a) $29 \mathrm{~g} / \mathrm{L}$

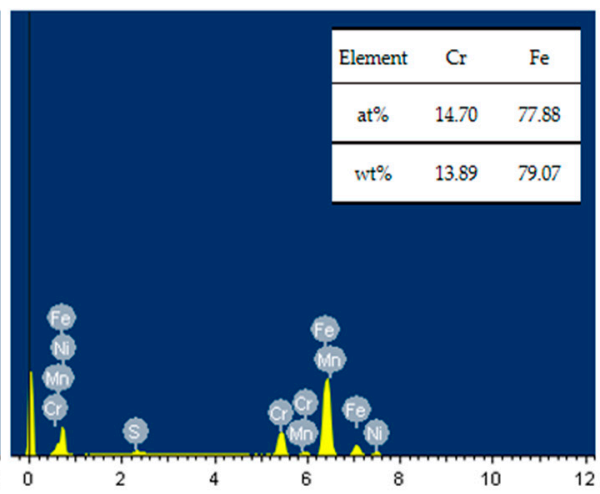

(b) $66 \mathrm{~g} / \mathrm{L}$

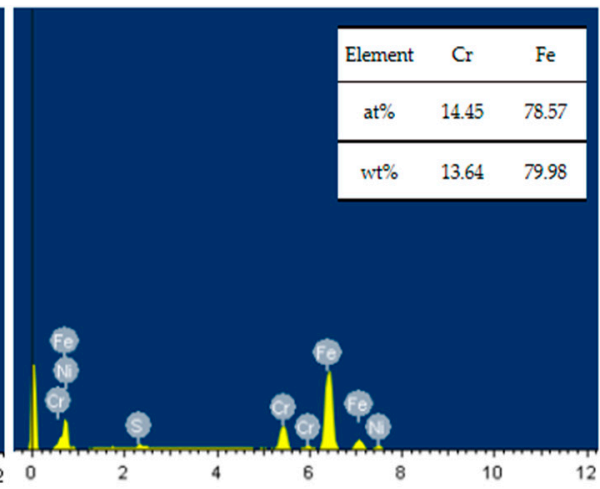

(c) $103 \mathrm{~g} / \mathrm{L}$

Figure 6. The EDS spectra of samples at different acid concentrations: (a) $29 \mathrm{~g} / \mathrm{L}$; (b) $66 \mathrm{~g} / \mathrm{L}$; and (c) $103 \mathrm{~g} / \mathrm{L}$. The result of sample soaked in solution with acid concentration of $48 \mathrm{~g} / \mathrm{L}$ is shown in Figure $5 b$.

The results show that the surface of stainless steel mainly contains Fe and Cr. Therefore, the main elements on the stainless-steel surface remained unchanged within the test conditions in this paper, while the contents of the main elements changed. The $\mathrm{Cr}$ element firstly increased and then decreased; the Fe element firstly decreased and then increased inversely, as shown in Figure 5. Figure 6 shows the EDS spectra with different sulfuric acid concentrations. An identical result to that shown in Figure 5 was obtained: the Cr element increased first and then decreased; the Fe element decreased first and then increased. Thus, it can be summarized that the $\mathrm{Cr}$ element increases firstly and then decreases, and the content of the Fe element decreases firstly and then increases with the acid concentration and duration.

Figure 7 shows the relationship between $\mathrm{Cr}$ and $\mathrm{Fe}$ and soak duration and acid concentration. As mentioned above, in order to improve the reliability of the results, the results are the average value of five regions. Figure 7a shows that the content of $\mathrm{Cr}$ on the surface of Super 13Cr increases first and then decreases as acidification duration increases. The content of $\mathrm{Cr}$ increased to about $14.1 \%$ after $50 \mathrm{~s}$ of soaking and then gradually decreased. Compared with the original sample, the content of $\mathrm{Cr}$ increased by about $4.1 \%$. In comparison, the content of Fe decreased in the first $50 \mathrm{~s}$ and then increased. 


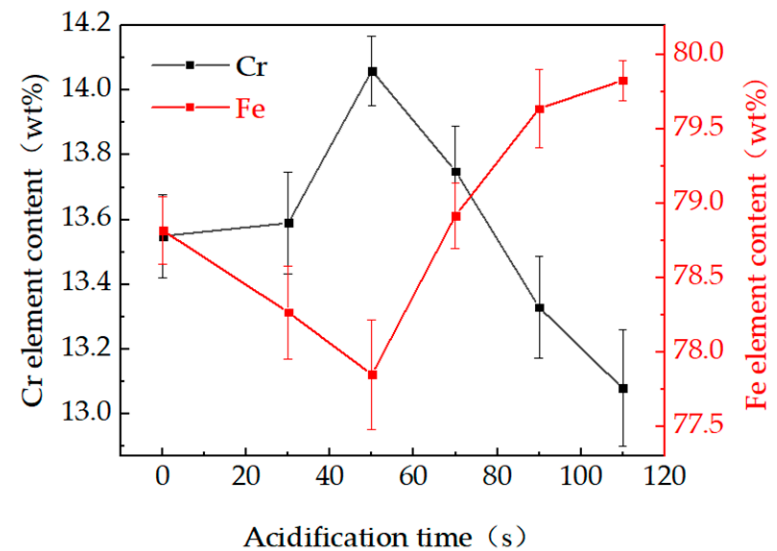

(a)

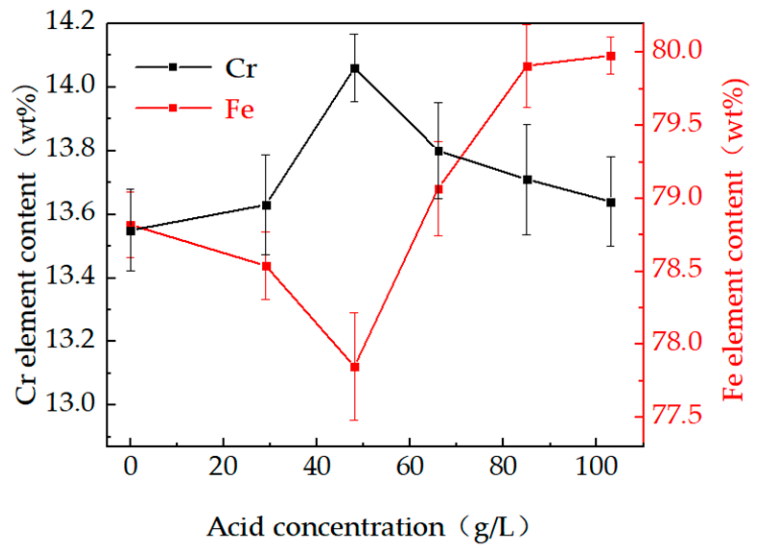

(b)

Figure 7. The content of $\mathrm{Cr}$ and Fe on Super $13 \mathrm{Cr}$ surface plotted as functions of the acidification parameters: (a) soaking duration; and (b) sulfuric acid concentration.

The soaking test was performed using different acid concentrations. In this experiment, the soaking duration was designed to be $50 \mathrm{~s}$. The $\mathrm{Cr}$ and Fe contents, depending on the acid concentration, are shown in Figure $7 \mathrm{~b}$. When the acid concentration is within the range of $0-48 \mathrm{~g} / \mathrm{L}$, the $\mathrm{Cr}$ content increases, and the $\mathrm{Cr}$ content gradually decreases when the acid concentration exceeds $48 \mathrm{~g} / \mathrm{L}$. On the contrary, within the acid concentration range of $0-48 \mathrm{~g} / \mathrm{L}$, the content of Fe elements decreases from $13.5 \%$ to $13.1 \%$ and then gradually increases when it exceeds $48 \mathrm{~g} / \mathrm{L}$.

To sum up, the highest $\mathrm{Cr}$ content and the lowest Fe content on the matrix surface could be obtained when an acid concentration of $48 \mathrm{~g} / \mathrm{L}$ and an acidification time of $50 \mathrm{~s}$ were selected during the acidification process. The enrichment of $\mathrm{Cr}$ on the matrix surface can enable it to form a thicker and denser corrosive product film on the material surface. The production of this film can effectively prevent the occurrence of pitting and significantly improve the stress corrosion cracking resistance of the material [36]. In addition, it was found that a high $\mathrm{Cr}$ content not only improves the uniform corrosion resistance, but also the local corrosion $[21,22,37]$.

The reason for the above phenomenon may be caused by the native film on the Super 13Cr. Based on the native film covering the austenitic stainless steel, we determined that the native film is mainly divided into two layers. The outer layer is an iron-nickel oxide layer, and the inner layer is a Cr-enriched layer [38-40]. On the basis of the results, the iron-nickel oxide outer layer dissolved once the sample was exposed to the sulfuric acid solution. As a result, the Fe content decreased during the initial exposure phase. The $\mathrm{Cr}$-enriched inner layer began to dissolve once the Fe-enriched outer layer had dissolved completely. Thus, when the acidification time and acid concentration increased to a critical value, the $\mathrm{Cr}$ content began decreasing, and the Fe began increasing, as shown in Figure 7.

Based on the above results, a reasonable parameter for pickling treatments could maximally improve the content of the $\mathrm{Cr}$ element on the surface before pre-passivation. Ultimately, a high-corrosion-resistance pre-passivation film could be fabricated on the Super 13Cr. The effect of the pickling parameter on the corrosion resistance of the Super $13 \mathrm{Cr}$ as tested by the electrochemical test is discussed in the next section.

\subsection{Electrochemical Test}

In order to test the effect of the pickling treatment on the corrosion resistance of the pre-passivation film on Super $13 \mathrm{Cr}$, the electrochemical performances of three types of samples were tested.

The potential difference between the working electrode and the reference electrode without load, that is, the electrode potential at zero current density, is open-circuit potential. 
This is a process of electrode change from instability to stability. Figure 8a shows the open-circuit potential curves of Super $13 \mathrm{Cr}$ with different pickling treatments. The test was terminated when the potential was independent of the time and gradually stabilized. The open circuit potentials were $-580 \mathrm{mV},-430 \mathrm{mV}$, and $-290 \mathrm{mV}$, which correspond to the native film and the films with pickling durations of $110 \mathrm{~s}$ and $50 \mathrm{~s}$, respectively. Thus, the corrosion resistance of the Super $13 \mathrm{Cr}$ could be improved by pre-passivation, and the pickling treatment parameters could also affect the corrosion resistance of the Super $13 \mathrm{Cr}$ in terms of the thermodynamics.

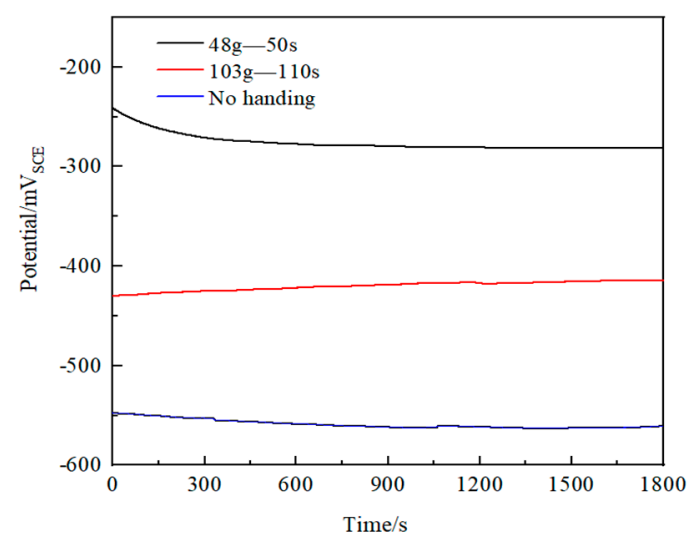

(a)

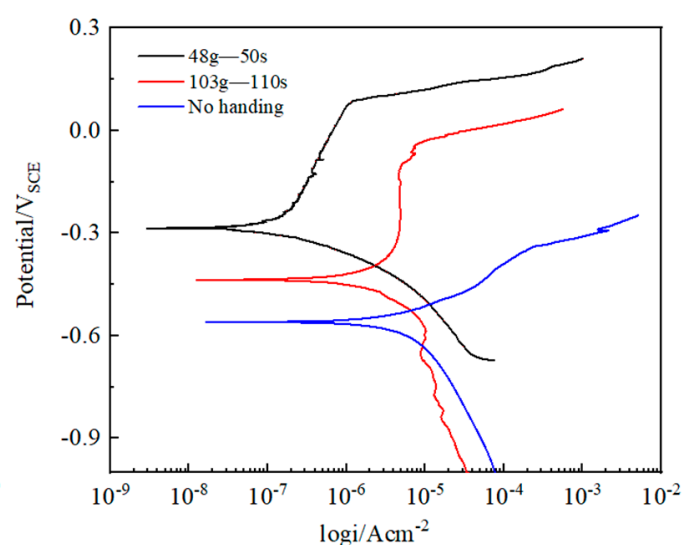

(b)

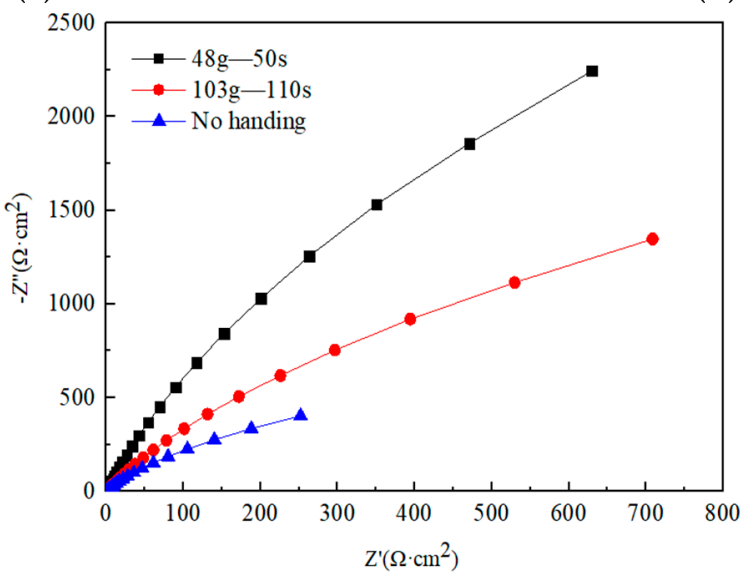

(c)

Figure 8. Results from electrochemical measurements. (a) the OCP versus pickling treatment parameters, (b) potentiodynamic polarization curves, and (c) Nyquist plots of the tested samples.

Figure $8 \mathrm{~b}$ shows the potentiodynamic polarization curves of the Super $13 \mathrm{Cr}$ that sustained pre-passivation with different pickling treatments. Obviously, there is no clear passivation behavior in the native sample. However, there is a relatively obvious passivation area in the pre-passivation samples. Compared with the Super $13 \mathrm{Cr}$ covered in the native film, the electrode potential of the pre-passivation sample increased, and the corrosion current density decreased. The corrosion current density derived from the Figure $8 \mathrm{~b}$ areshown in Table 2. The corrosion current density of the original sample with native film was $10.542 \mu \mathrm{A} / \mathrm{cm}^{2}$. The current density of the sample with pickling parameters of $48 \mathrm{~g} / \mathrm{L}$ and $50 \mathrm{~s}$ was $0.266 \mu \mathrm{A} / \mathrm{cm}^{2}$. The current density of the sample with pickling parameters of $103 \mathrm{~g} / \mathrm{L}$ and $110 \mathrm{~s}$ was $7.291 \mu \mathrm{A} / \mathrm{cm}^{2}$. Obviously, the untreated sample has the highest corrosion rate in a $3.5 \% \mathrm{NaCl}$ solution. When the pickling parameters are $48 \mathrm{~g} / \mathrm{L}$ and $50 \mathrm{~s}$, the current density of the sample decreases by about $97 \%$. In comparison, the current density of the sample decreased by about $31 \%$ when the pickling parameters are $103 \mathrm{~g} / \mathrm{L}$ and $110 \mathrm{~s}$. Thus, the pre-passivation has a passive effect on the Super $13 \mathrm{Cr}$ in terms of the 
corrosion resistance. In addition, the corrosion resistance could be improved by a factor of about 40 via a change in the pickling parameter.

Table 2. Corrosion current densities of the pre-passivation films with different pickling conditions.

\begin{tabular}{cccc}
\hline Pickling Parameters & Native Film & $\mathbf{4 8} \mathbf{g} / \mathbf{L}-\mathbf{5 0 ~ s}$ & $\mathbf{1 0 3} \mathbf{~} / \mathbf{L}-\mathbf{1 1 0 ~ s}$ \\
\hline Icorr $/\left(\mu \mathrm{A} / \mathrm{cm}^{2}\right)$ & 10.542 & 0.266 & 7.291 \\
\hline
\end{tabular}

The Nyquist plots are presented in Figure 8c. All the Nyquist plots exhibit a single semicircle, suggesting a similar passive mechanism, and the pre-passive films are intact. The diameters of the plots of the pre-passivated samples are larger than those of the original samples with native film, and the diameters of the plots change with the pickling treatment parameters. This means that the corrosion resistance of the Super $13 \mathrm{Cr}$ increases with the film thickness, consistent with the polarization results.

On the basis of the above the results, the pre-passivation process has a greatly positive effect on the corrosion resistance of Super $13 \mathrm{Cr}$; the pickling treatment could affect the pre-passivated film and then affect the corrosion resistance of the Super $13 \mathrm{Cr}$ in terms of the thermodynamics and the dynamics.

\section{Conclusions}

(1) The size and morphology of the inclusion on the surface of the Super $13 \mathrm{Cr}$ employed in this case basically do not change after soaking in a dilute sulfuric acid solution, but the $\mathrm{Cr}$ content in the matrix/inclusion transition area increases after acidification and the Fe content decreases.

(2) The Cr content on the surface of stainless steel increases first and then decreases with the soaking duration and acid concentration. On the contrary, the Fe content decreases first and then increases. The content of the $\mathrm{Cr}$ element reaches the peak value, and the content of Fe element is at the valley when the soaking time and the acid concentration are $50 \mathrm{~s}$ and $48 \mathrm{~g} / \mathrm{L}$.

(3) Compared with the original sample with native film, the corrosion resistance of the pre-passivated Super $13 \mathrm{Cr}$ improves dramatically in terms of the thermodynamics and the dynamics. The corrosion resistance in this case could be maximally improved by a factor of about 40 by changing the pickling parameters in the pre-passivation process, according to the corrosion current density.

(4) The dissolution of the native film on the Super $13 \mathrm{Cr}$ surface during the pickling treatment could be divided into two phases, including the outer film dissolution phase and the inner film dissolution phase. The pickling treatment affects the corrosion resistance through the chemical composition of the pre-passivation film. The corrosion resistance would be greatly improved if only the Fe-enriched outer film dissolves instead of dissolving the whole native film during the pickling treatment.

Author Contributions: Conceptualization, H.D. and Y.H.; data curation, Z.L.; formal analysis, Z.L.; investigation, Z.L.; methodology, Y.-M.L.; resources, H.D.; software, W.-Y.Z. and Z.L.; validation, L.S.; writing—original draft, Z.L.; writing—review and editing, H.D. and Y.H. All authors have read and agreed to the published version of the manuscript.

Funding: The research was funded by the National Natural Science Foundation of China (51904331), the Natural Science Foundation Research Project of Shaanxi Province (No. 2020JM-540), the State Key Laboratory for Mechanical Behavior of Materials (No. 20202210), the Materials Science and Engineering of Provincial Advantage Disciplines in Xi'an Shiyou University (No. YS37020203), and the Xi'an Shiyou University Graduate Innovation and Practice Ability Training Project (YCS20211043).

Institutional Review Board Statement: Not applicable.

Informed Consent Statement: Not applicable.

Data Availability Statement: Data sharing is not applicable to this article. 
Acknowledgments: The guidance and help of Yong Zhou and Xiao Li from Xi'an Shiyou University are greatly acknowledged.

Conflicts of Interest: The authors declare no conflict of interest.

\section{References}

1. Zhu, G.Y.; Li, Y.Y.; Hou, B.S.; Zhang, Q.H.; Zhang, G.A. Corrosion behavior of $13 \mathrm{Cr}$ stainless steel under stress and crevice in high pressure $\mathrm{CO}_{2} / \mathrm{O}_{2}$ environment. J. Mater. Sci. Technol. 2021, 88, 79-89. [CrossRef]

2. Xiao, G.Q.; Tan, S.Z.; Yu, Z.M.; Dong, B.J.; Yi, Y.G.; Tian, G.; Yu, H.Y.; Shi, S.Z. Study on $\mathrm{CO}_{2}$ corrosion behavior of super 13Cr steel in high temperature steam environment. Petroleum 2020, 6, 106-113. [CrossRef]

3. Li, K.Y.; Zeng, Y.M.; Luo, J.L. Influence of $\mathrm{H}_{2} \mathrm{~S}$ on the general corrosion and sulfide stress cracking of pipelines steels for supercritical $\mathrm{CO}_{2}$ transportation. Corros. Sci. 2021, 190, 109639. [CrossRef]

4. Akpanyung, K.V.; Loto, R.T. Pitting corrosion evaluation: A review. J. Phys. Conf. Ser. 2019, 1378, 022088. [CrossRef]

5. Williams, D.E.; Zhu, Y.Y. Explanation for Initiation of Pitting Corrosion of Stainless Steels at Sulfide Inclusions. J. Electrochem. Soc. 2000, 147, 1763-1766. [CrossRef]

6. Pickering, H.W.; Frankenthal, R.P. On the Mechanism of Localized Corrosion of Iron and Stainless Steel: I. Electrochemical Studies. J. Electrochem. Soc. 1972, 119, 1297-1304. [CrossRef]

7. Li, X.P.; Zhao, Y.; Qi, W.L.; Xie, J.X.; Wang, J.L.; Liu, B.; Zeng, G.X.; Zhang, T.; Wang, F.H. Effect of extremely aggressive environment on the nature of corrosion scales of HP-13Cr stainless steel. Appl. Surf. Sci. 2019, 469, 146-161. [CrossRef]

8. Zhang, Z.; Zheng, Y.S.; Li, J.; Liu, W.Y.; Liu, M.Q.; Gao, W.X.; Shi, T.H. Stress corrosion crack evaluation of super $13 C r$ tubing in high-temperature and high-pressure gas wells. Eng. Fail. Anal. 2019, 95, 263-272. [CrossRef]

9. Lei, X.W.; Feng, Y.R.; Zhang, J.X.; Fu, A.Q.; Yin, C.X.; Digby, D.M. Impact of reversed austenite on the pitting corrosion behavior of super 13Cr martensitic stainless steel. Electrochimica Acta 2016, 191, 640-650. [CrossRef]

10. Lei, X.W.; Wang, H.Y.; Wang, N.; Ren, D.Z.; Fu, A.Q.; Yin, C.X.; Zhang, J.P.; Feng, Y.R. Passivity of martensitic stainless steel in borate buffer solution: Influence of sulfide ion. Appl. Surf. Sci. 2019, 478, 255-265. [CrossRef]

11. Gu, Y.; Wu, H.B.; Yuan, R.; Zhang, P.C.; Zhang, Z.H.; Song, S. Effect of Temperature and Composition on Corrosion Behavior of Medium $\mathrm{Cr}$ Steel in a Salt Solution Containing $\mathrm{CO}_{2}$. Corrosion 2021, 77, 655-667. [CrossRef]

12. Zhao, Y.G.; Liu, W.; Fan, Y.M.; Zhang, T.Y.; Dong, B.J.; Chen, L.J.; Wang, Y.B. Influence of microstructure on the corrosion behavior of super 13Cr martensitic stainless steel under heat treatment. Mater. Charact. 2021, 175, 111066. [CrossRef]

13. Kultamaa, M.; Mönkkönen, K.; Saarinen, J.J.; Suvanto, M. Corrosion Protection of Injection Molded Porous 440C Stainless Steel by Electroplated Zinc Coating. Coatings 2021, 11, 949. [CrossRef]

14. Zhao, Y.G.; Liu, W.; Dong, B.J.; Wang, Y.T.; Fan, Y.M.; Zhang, T.Y.; Banthukul, W.T. Effects of Microstructure and Material Composition on the Formation Kinetics of Passive Film and Pitting Behavior of Super 13Cr Stainless Steel. Metall. Mater. Trans. A 2021, 52, 1985-1998. [CrossRef]

15. Sun, Y.T.; Tan, X.; Lei, L.L.; Li, J. Revisiting the effect of molybdenum on pitting resistance of stainless steels. Tungsten 2021, 3 , 329-333. [CrossRef]

16. Jang, H.J.; Kwon, H.S. In situ study on the effects of Ni and Mo on the passive film formed on Fe-20Cr alloys by photoelectrochemical and Mott-Schottky techniques. J. Electroanal. Chem. 2006, 590, 120-125. [CrossRef]

17. Feng, Y.Q.; Du, Z.X.; Hu, Z.F. Effect of Ni Addition on the Corrosion Resistance of NiTi Alloy Coatings on AISI 316L Substrate Prepared by Laser Cladding. Coatings 2021, 11, 1139. [CrossRef]

18. Loable, C.; Vicosa, I.N.; Mesquita, T.J.; Mantel, M.; Nogueira, R.P.; Berthomé, G.; Chauveau, E.; Roche, V. Synergy between molybdenum and nitrogen on the pitting corrosion and passive film resistance of austenitic stainless steels as a PH-dependent effect. Mater. Chem. Phys. 2017, 186, 237-245. [CrossRef]

19. Moon, J.; Ha, H.Y.; Park, S.J.; Lee, T.H.; Jang, J.H.; Lee, C.H.; Han, H.N.; Hong, H.U. Effect of Mo and Cr additions on the microstructure, mechanical properties and pitting corrosion resistance of austenitic Fe-30Mn-10.5Al-1.1C lightweight steels. J. Alloys Compd. 2019, 775, 1136-1146. [CrossRef]

20. Qi, X.; Mao, H.H.; Yang, Y.T. Corrosion behavior of nitrogen alloyed martensitic stainless steel in chloride containing solutions. Corros. Sci. 2017, 120, 90-98. [CrossRef]

21. Xu, L.N.; Xu, X.Q.; Yin, C.X.; Qiao, L.J. $\mathrm{CO}_{2}$ corrosion behavior of $1 \% \mathrm{Cr}-13 \% \mathrm{Cr}$ steel in relation to Cr content changes. Mater. Res. Express 2019, 6, 096512. [CrossRef]

22. Liu, X.Q.; Liu, Z.L.; Hu, J.D.; Hou, Z.G.; Tian, Q.C.; Wang, H.Z. Influence of Cr Content on Corrosion Behaviour of Tube Pile Steel in Half-Immersion Environment. Trans. Indian Inst. Met. 2018, 71, 209-218. [CrossRef]

23. JFE Steel Corporation. Martensitic Stainless Steel Seamless Pipe For Oil Country Tubular Goods, And Method For Manufacturing Same. In Patent Application Approval Process; USPTO 20200283866; Energy Weekly News; JFE Steel Corporation: Tokyo, Japan, 2020.

24. Ćurković, L.; Otmačić, Ć.H.; Žmak, I.; Mustafa, M.K.; Gabelica, I. Corrosion Behavior of Amorphous Sol-Gel TiO $2-\mathrm{ZrO}_{2} \mathrm{Nano}$ Thickness Film on Stainless Steel. Coatings 2021, 11, 988. [CrossRef]

25. Tadahiro, O.; Atsushi, O.; Masakazu, N.; Kawada, K.; Watanabe, T.; Nakagawa, Y.; Miyoshi, S.; Takahashi, S.; Chen, M.S. The Technology of Chromium Oxide Passivation on Stainless Steel Surface. J. Electrochem. Soc. 2019, 140, 1691-1699. [CrossRef] 
26. Wegrelius, L.; Falkenberg, F.; Olefjord, I. Passivation of Stainless Steels in Hydrochloric Acid. J. Electrochem. Soc. 2019, 146, 1397-1406. [CrossRef]

27. Hou, Y.; Zhao, J.; Cao, T.S.; Zhang, L.; Meng, X.M.; Zhang, Z.P.; Cheng, C.Q. Improvement on the pitting corrosion resistance of 304 stainless steel via duplex passivation treatment. Mater. Corros. 2019, 70, 1764-1775. [CrossRef]

28. Li, M.; Pascalidou, E.M.; Wiame, F.; Zanna, S.; Maurice, V.; Marcus, P. Passivation mechanisms and pre-oxidation effects on model surfaces of FeCrNi austenitic stainless steel. Corros. Sci. 2020, 167, 108483. [CrossRef]

29. Zhang, C.Y.; Wei, Y.H.; Yang, J.; Li, J.; Emori, W. Effects of nitric acid passivation on the corrosion behavior of ZG06Cr13Ni4Mo stainless steel in simulated marine atmosphere. Mater. Corros. 2020, 71, 1576-1590. [CrossRef]

30. Li, J.D.; Chen, C.; Zhang, S.J.; Lin, B.; Wng, Y.Y.; Zhu, Y.Q.; Tang, J.L. Research progress on localized corrosion behavior of stainless steel under different stress conditions. Surf. Technol. 2021, 50, 101-115. [CrossRef]

31. Chen, X.R.; Cheng, G.G.; Li, J.Y.; Hou, Y.Y.; Pan, J.X.; Ruan, Q. Characteristics and Formation Mechanism of Inclusions in 304L Stainless Steel during the VOD Refining Process. Metals 2018, 8, 1024. [CrossRef]

32. Park, J.H.; Todoroki., H. Control of MgO·Al2O3 Spinel Inclusions in Stainless Steels. ISIJ Int. 2010, 50, 1333-1346. [CrossRef]

33. Kent, P.; Yang, S.F.; Li, J.S.; Zhang, L.F.; Wang, Z.F. Behavior of $\mathrm{MgO} \cdot \mathrm{Al}_{2} \mathrm{O}_{3}$ Based Inclusions in Alloy Steel During Refining Process. J. Iron Steel Res. Int. 2010, 17, 1-6. [CrossRef]

34. Cheng, R.J.; Li, R.C.; Cheng, D.; Liu, J.S.; Fang, Q.; Zhou, J.A.; Dong, W.L.; Zhang, H.; Ni, H.W. Revolution and Control of Fe-Al-(Mg, Ti)-O Oxide Inclusions in IF Steel during 260t BOF-RH-CC Process. Metals 2020, 10, 528. [CrossRef]

35. Wang, C.G.; Ma, R.Y.; Zhou, Y.T.; Liu, Y.; Daniel, E.F.; Li, X.F.; Wang, P.; Dong, J.H.; Ke, W. Effects of rare earth modifying inclusions on the pitting corrosion of 13Cr4Ni martensitic stainless steel. J. Mater. Sci. Technol. 2021, 93, 232-243. [CrossRef]

36. Sun, B.Z.; Zuo, X.M.; Cheng, X.J.; Li, X.G. The role of chromium content in the long-term atmospheric corrosion process. NPJ Mater. Degrad. 2020, 4. [CrossRef]

37. Zhang, T.Y.; Xu, X.X.; Li, Y.; Lv, X.W. The function of $\mathrm{Cr}$ on the rust formed on weathering steel performed in a simulated tropical marine atmosphere environment. Constr. Build. Mater. 2021, 277, 122298. [CrossRef]

38. Wang, Z.C.; Paschalidou, E.M.; Seyeux, A.; Zanna, S.; Maurice, V.; Marcus, P. Mechanisms of Cr and Mo Enrichments in the Passive Oxide Film on 316L Austenitic Stainless Steel. Front. Mater. 2019, 6. [CrossRef]

39. Tian, H.Y.; Sun, F.L.; Chu, F.Z.; Wang, L.W.; Wang, X.; Cui, Z.Y. Passivation behavior and surface chemistry of 316 SS in the environment containing $\mathrm{Cl}^{-}$and $\mathrm{NH}^{4+}$. J. Electroanal. Chem. 2021, 886, 115138. [CrossRef]

40. Kim, E.T.; Muhammad, I.; Han, J.C.; Ko, K.K.; Bae, H.J.; Sung, H.; Kim, G.J.; Seol, J.B. Near atomic-scale comparison of passive film on a $17 \mathrm{wt} \%$ Cr-added $18 \mathrm{wt} \%$ Mn steel with those on typical austenitic stainless steels. Scr. Mater. 2021, 203, 114112. [CrossRef] 